\title{
Triple therapy versus sequential therapy for the first-line Helicobacter pylori eradication
}

\author{
Ji Young Chang, Ki-Nam Shim*, Chung Hyun Tae, Ko Eun Lee, Jihyun Lee, Kang Hoon Lee, Chang Mo Moon, \\ Seong-Eun Kim, Hye-Kyung Jung and Sung-Ae Jung
}

\begin{abstract}
Background: The eradication rate of Helicobacter pylori (H. pylori) with triple therapy which was considered as standard first-line treatment has decreased to $70-85 \%$. The aim of this study is to compare 7 -day triple therapy versus 10-day sequential therapy as the first line treatment.

Methods: Data of $1240 \mathrm{H}$. pylori positive patients treated with triple therapy or sequential therapy from January 2013 to December 2015 were analyzed retrospectively. The patients who had undertaken previous H. pylori eradication therapy or gastric surgery were excluded.

Results: There were 872 (74.3\%) patients in the triple therapy group, and 302 (25.7\%) patients in the sequential therapy group. There was no significant difference between the two groups regarding age, residence, comorbidities or drug compliance, but several differences were noted in endoscopic characteristics and indication for the treatment. The eradication rate of $\mathrm{H}$. pylori by intention to treat analysis was $64.3 \%$ in the triple therapy group, and $81.9 \%$ in the sequential therapy group $(P=0.001)$. In per protocol analysis, $H$. pylori eradication rate in the triple therapy and sequential therapy group was 81.9 and $90.3 \%$, respectively $(P=0.002)$. There was no significant difference in overall adverse events between the two groups $(P=0.706)$. For the rescue therapy, bismuth-containing quadruple therapy showed comparable treatment efficacy after sequential therapy, as following triple therapy.
\end{abstract}

Conclusions: The eradication rate of triple therapy was below the recommended threshold. Sequential therapy could be effective and tolerable candidate for the first-line H. pylori eradication therapy.

Keywords: Helicobacter pylori, Anti-bacterial agents, First-line triple therapy, Sequential therapy

\section{Background}

The prevalence of Helicobacter pylori (H. pylori) infection has decreased over the past decade, changed from 66.9 to $54.4 \%$ between 1998 and 2011, but its prevalence is still high in Korea [1]. H. pylori infection is a known risk factor of upper gastrointestinal diseases, such as chronic gastritis, peptic ulcer disease, mucosa-associated lymphoid tissue (MALT) lymphoma, and gastric cancer $[2,3]$. Eradication of $H$. pylori reduces the recurrence rate of peptic ulcer disease or recurrent gastric cancer after endoscopic resection of early gastric cancer, and it also induces the remission of MALT lymphoma [4-6]. Therefore, H. pylori eradication has critical role in

\footnotetext{
* Correspondence: shimkn@ewha.ac.kr

Department of Internal Medicine, Ewha Womans University School of

Medicine, Ewha Medical Research Institute, 1071 Anyangcheon-ro,

Yangcheon-gu, Seoul 158-710, South Korea
}

promoting national health in Korea, where $95 \%$ of confirmed $H$. pylori strains have highly virulent East Asiantype cytotoxin-associated gene A which is potent in causing gastric cancer $[7,8]$.

Triple therapy (TT) consists of proton-pump inhibitor (PPI), clarithromycin, and amoxicillin has been considered as standard first-line treatment for $H$. pylori in Korea since 1998 [9]. Recently updated Korean guideline also recommended TT as the first-line regimen [10]. However, the efficacy of TT has decreased progressively. The recent nationwide survey reported the decreasing trend of eradication rate of TT which was $84.9-87.5 \%$ from 2001 to 2007, but $80.0-81.4 \%$ from 2008 to $2010(P<0.0001)[11]$. The most important factor of reduced efficacy of TT is increasing antibiotic resistance of $H$. pylori, especially to clarithromycin [12]. The primary resistance rate to clarithromycin increased from 
23.7 to $71.2 \%$, whereas amoxicillin increased from 6.3 to $14.9 \%$ during the period of 2003-2012 [13].

Therefore, several protocols have been suggested in order to overcome treatment failure of TT, including the extending of treatment duration, the use of four-drug regimen such as sequential therapy (SET), concomitant therapy, hybrid therapy, and the prescription of novel antibiotics such as levofloxacin [14]. Reasonable treatment regimens need to attain $H$. pylori eradication rate of higher than $80.0 \%$ by intention to treat (ITT) analysis, and higher than $90.0 \%$ by per protocol (PP) analysis $[15,16]$. Several previous meta-analyses reported the superiority of SET than TT $[17,18]$, whereas other studies revealed conflicting results $[19,20]$.

In Ewha Womans University Medical Center, SET has been tried as an alternative first-line treatment for H. pylori since 2013. So, we aimed to compare 7-day TT with 10-day SET as the first line treatment in our medical center. We also evaluated the adverse events of the two regimens, clinical factors associated with successful eradication, and effectiveness of the second line treatment after these two treatments.

\section{Methods}

\section{Study subjects}

From January 2013 to December 2015, 1240 patients who were older than 18-year old, diagnosed with $H$. pylori infection and treated with TT or SET at Ewha Womans University Hospital were enrolled retrospectively. H. pylori infection was confirmed by histology, rapid urease test (HP Kit ${ }^{\mathrm{m}}$, Jongkeundang, Korea), C-urea breath test or serum $H$. pylori anti-body test. At least 4 weeks after treatment, $H$. pylori eradication was demonstrated by any of these tests. The patients who had undertaken previous $H$. pylori eradication therapy or gastric surgery were excluded.

We evaluated demographic information, residence area, current status of smoking and alcohol consumption, comorbidities, endoscopic diagnosis, indication for H. pylori eradication, drug compliance, and treatmentrelated adverse events through medical records review. Endoscopic findings and the results of endoscopic biopsies were also reviewed retrospectively. For detailed analysis, drug compliance was divided into two categories; good or poor compliance. Good compliance was defined if the patient took more than $80 \%$ of the prescribed medicine, and who took less than $80 \%$ of prescribed medicine was belonged to poor compliance group. For the PP analysis, patients who were poorly compliant or lost to follow-up were excluded.

Standard TT for seven days consists of twice a day amoxicillin (1000 mg), clarithromycin (500 mg), and standard dose of PPI. SET for 10 days consists of twice a day amoxicillin (1000 mg), standard dose of PPI for
5 days, followed by twice a day clarithromycin $(500 \mathrm{mg})$, metronidazole $(500 \mathrm{mg}$ ), and standard dose of PPI for another 5 days.

This study was approved by the Institutional Review Board of our medical center (IRB number; 2016-04051-002).

\section{Statistical analyses}

All statistical analyses were performed with using SPSS program, version 22.0. Continuous variables were reported as the mean with the standard deviation. To analyze the baseline clinical characteristics, adverse events and eradication rates between the two groups, Student $t$-test or the Mann-Whitney $U$ test was used for continuous variables, and the chi-square or the Fisher's exact test was used for categorical variables. $H$. pylori eradication rates were demonstrated by ITT and PP analyses. Univariate and multivariate logistic regression were performed for evaluating independent associated factors with successful $H$. pylori eradication. The $P$ value of $<0.05$ was considered as statistical significance.

\section{Results}

\section{Baseline characteristics}

A total of 1240 patients received $H$. pylori eradication therapy from January 2013 to December 2015. After excluding 66 patients who had previous $H$. pylori eradication or gastric surgery, 1174 patients were included finally. There were 872 patients in the TT group and 302 patients in the SET group. A detailed flowchart of the enrolled patients is shown in Fig. 1. The baseline characteristics of the study population are summarized in Table 1. There was no significant difference between the two groups regarding age, residence, comorbidities or drug compliance. But, more males and more patients who were diagnosed with $H$. pylori infection by histology were included in the SET group than the TT group. Several differences were found in the endoscopic

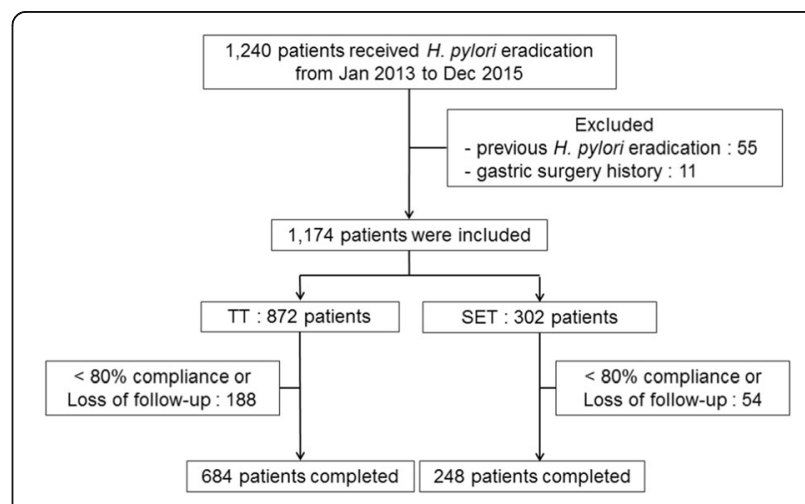

Fig. 1 The flowchart of enrolled patients. H. pylori Helicobacter pylori, Jan January, Dec December, $\Pi$ T triple therapy, SET sequential therapy 
Table 1 Baseline clinical characteristics

\begin{tabular}{|c|c|c|c|}
\hline & $\pi$ & SET & $P$ value \\
\hline & $\begin{array}{l}N=872 \\
(74.3 \%)\end{array}$ & $\begin{array}{l}N=302 \\
(25.7 \%)\end{array}$ & \\
\hline Age (mean $\pm S D)$ & $52.26 \pm 13.52$ & $51.83 \pm 12.17$ & 0.607 \\
\hline Male & $477(54.7)$ & $192(63.6)$ & 0.007 \\
\hline Residence & & & 0.510 \\
\hline Seoul & $695(79.7)$ & $246(81.5)$ & \\
\hline Another area & $177(20.3)$ & $56(18.5)$ & \\
\hline Smoking & $217(24.9)$ & $113(37.4)$ & $<0.001$ \\
\hline Alcohol & $389(41.3)$ & $91(39.2)$ & $<0.001$ \\
\hline Diabetes mellitus & $98(11.2)$ & $33(10.9)$ & 0.882 \\
\hline Hypertension & $185(21.2)$ & $71(23.5)$ & 0.405 \\
\hline Chronic kidney disease & $12(1.4)$ & $4(1.3)$ & 0.999 \\
\hline Chronic liver disease & $24(2.8)$ & $7(2.3)$ & 0.685 \\
\hline Ischemic heart disease & $23(2.6)$ & $12(4.0)$ & 0.239 \\
\hline Compliance $>80 \%$ & $707(81.1)$ & $256(84.8)$ & 0.150 \\
\hline H. pylori test & & & $<0.001$ \\
\hline Histology & 293 (33.6) & $182(60.3)$ & \\
\hline Rapid urease test & $586(64.9)$ & $116(38.4)$ & \\
\hline Urea breath test & $8(0.9)$ & $2(0.7)$ & \\
\hline Serology & $5(0.6)$ & $2(0.7)$ & \\
\hline \multicolumn{4}{|l|}{ Endoscopic diagnosis } \\
\hline Chronic gastritis & $201(23.1)$ & $31(10.3)$ & $<0.001$ \\
\hline Atrophy or metaplasia & $332(38.1)$ & $141(46.7)$ & 0.009 \\
\hline Gastric ulcer & $274(31.4)$ & $119(39.4)$ & 0.011 \\
\hline Duodenal ulcer & $331(38.0)$ & 89 (29.5) & 0.008 \\
\hline Duodenitis & $52(6.0)$ & $18(6.0)$ & 0.998 \\
\hline \multicolumn{4}{|l|}{ Indication of H. pylori eradication } \\
\hline Peptic ulcer disease & $522(59.9)$ & $148(49.0)$ & 0.001 \\
\hline Endoscopic resection of EGC & $21(2.4)$ & $24(7.9)$ & $<0.001$ \\
\hline Endoscopic resection of adenoma & $36(4.1)$ & $24(7.9)$ & 0.009 \\
\hline MALT Iymphoma & $4(0.5)$ & $2(0.7)$ & 0.651 \\
\hline H. pylori gastritis & $83(9.5)$ & $23(7.6)$ & 0.320 \\
\hline Atrophy or metaplasia & $130(14.9)$ & $61(20.2)$ & 0.032 \\
\hline
\end{tabular}

$\pi$ triple therapy, SET sequential therapy, SD standard deviation, H. pylori Helicobacter pylori, EGC early gastric cancer, MALT mucosa associated lymphoid tissue

characteristics - atrophy or metaplastic gastritis $(P=0.009)$, and gastric ulcers $(P=0.011)$ were more prevalent in the SET group, whereas chronic gastritis $(P<0.001)$ and duodenal ulcers $(P=0.008)$ were more prevalent in the TT group. In terms of indication of $H$. pylori eradication, significantly higher portion of patients received SET after endoscopic resection of gastric neoplasms such as early gastric cancers $(P<0.001)$ or gastric adenomas $(P=0.009)$.

\section{H. pylori eradication rates}

Among 872 patients receiving first-line TT, 684 (78.4\%) patients completed the treatment with good compliance.
In the SET group, $248(82.1 \%)$ patients completed the treatment with good compliance in total of 302 patients. The eradication rate of SET was significantly higher than TT by both ITT $(P=0.001)$ and PP $(P=0.002)$ analyses. The TT showed the eradication rate of 64.3 and $81.9 \%$ by ITT and PP analyses, respectively. The overall eradication rate of SET was 81.9 in ITT, and $90.3 \%$ in PP analysis (Fig. 2).

\section{Clinical factors related to the $H$. pylori eradication}

Possible clinical factors related to successful $H$. pylori eradication were also analyzed. But, there were no statistically significant factors to predict successful eradication in both univariate and multivariate analyses (Table 2).

\section{Comparison of treatment-related adverse events}

During the treatment, $33(3.8 \%)$ patients in the TT group, and $10(3.3 \%)$ patients in the SET group had treatment-related adverse events. The most common adverse event was diarrhea (1.3\% versus (vs.) $1.7 \%$; TT vs. SET), followed by nausea or vomiting in both groups. But, there was no significant difference in the rate of specific adverse event as well as overall adverse events between the two groups (Table 3 ).

\section{Second-line eradication therapy after first-line eradication failure}

A detailed flow-chart of second-line eradication therapy after failure of first-line eradication therapy is shown in Fig. 3. Among 124 (18.1\%) patients who failed in firstline TT, 109 patients received second-line eradication therapy; $28.4 \%$ for bismuth-containing quadruple therapy (BCQT) for 7 days (BCQT-7), 68.8\% for BCQT for 14 days (BCQT-14), and $2.8 \%$ of patients for TT for 7 days. Data from the patients who received second-line TT could not be included for further analyses because of poor compliance or loss of follow-up. The eradication rate in patients who received BCQT-7 after failing

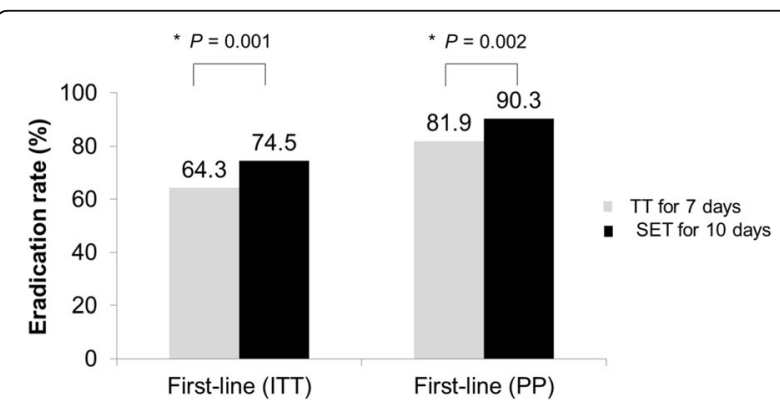

Fig. 2 Comparison of eradication rate of Helicobacter pylori with firstline triple therapy with sequential therapy. The eradication rate of SET was significantly higher than TT by both ITT $(P=0.001)$ and PP $(P=0.002)$ analyses. $T$ triple therapy, SET sequential therapy, ITT intention to treat, PP per protocol 
Table 2 Clinical factors related to successful Helicobacter pylori eradication

\begin{tabular}{|c|c|c|c|c|c|c|}
\hline & \multicolumn{3}{|l|}{$\pi$} & \multicolumn{3}{|l|}{ SET } \\
\hline & OR & $95 \% \mathrm{Cl}$ & $P$ value & OR & $95 \% \mathrm{Cl}$ & $P$ value \\
\hline \multicolumn{7}{|l|}{ Univariate analyses } \\
\hline Male gender & 0.941 & $0.637-1.391$ & 0.761 & 1.039 & $0.436-2.477$ & 0.932 \\
\hline Age $<50$ years & 0.724 & $0.481-1.089$ & 0.121 & 1.634 & $0.702-3.807$ & 0.255 \\
\hline Residence - Seoul & 0.819 & $0.509-1.320$ & 0.413 & 1.154 & $0.375-3.553$ & 0.803 \\
\hline Alcohol & 0.942 & $0.628-1.415$ & $0 . .775$ & 0.909 & $0.391-2.115$ & 0.824 \\
\hline Smoking & 0.883 & $0.553-1.411$ & 0.602 & 0.802 & $0.329-1.955$ & 0.628 \\
\hline Diabetes mellitus & 1.375 & $0.770-2.455$ & 0.281 & 1.190 & $0.330-4.289$ & 0.790 \\
\hline Hypertension & 0.933 & $0.579-1.502$ & 0.775 & 1.131 & $0.426-2.999$ & 0.805 \\
\hline \multicolumn{7}{|l|}{ Indication } \\
\hline Peptic ulcer disease & 0.690 & $0.456-1.043$ & 0.079 & 1.559 & $0.567-4.284$ & 0.389 \\
\hline Malignant disease & 0.647 & $0.297-1.410$ & 0.273 & 1.604 & $0.461-5.581$ & 0.458 \\
\hline \multicolumn{7}{|l|}{ Multivariate analysis } \\
\hline Male gender & 0.941 & $0.635-1.394$ & 0.761 & 1.013 & $0.419-2.449$ & 0.976 \\
\hline Age $<50$ years & 0.718 & $0.476-1.083$ & 0.114 & 1.708 & $0.717-4.068$ & 0.227 \\
\hline Residence - Seoul & 0.792 & $0.490-1.282$ & 0.343 & 1.203 & $0.280-3.831$ & 0.750 \\
\hline \multicolumn{7}{|l|}{ Indication } \\
\hline Peptic ulcer disease & 0.679 & $0.447-1.030$ & 0.069 & 1.538 & $0.554-4.272$ & 0.409 \\
\hline Malignant disease & 0.607 & $0.277-1.330$ & 0.212 & 1.877 & $0.517-6.817$ & 0.338 \\
\hline
\end{tabular}

$\pi$ triple therapy, SET sequential therapy, OR odds ratio, $\mathrm{Cl}$ confidence interval

first-line TT was 71.0 and $84.0 \%$ by ITT and PP analysis; eradication rate for BCQT-14 after TT was 85.3 and 95.5\% by ITT and PP analysis, respectively. Twenty-four (9.7\%) patients failed at their first-line SET, and $22 \mathrm{pa-}$ tients received BCQT-14 which showed the eradication rate of $72.7 \%$ in ITT and $84.2 \%$ in PP analysis. We found no significant differences in the overall eradication rates, compliance, adverse events between any of these three groups (Table 4).

The most common complication after second-line treatment was nausea or vomiting in all of three groups.
After failure of second-line eradication therapy in the SET group, two patients refused further treatment, and one patient received third-line eradication therapy consisted with twice a day standard dose of PPI, amoxicillin (1000 mg), and levofloxacin (500 mg) for 7 days. But, eradication of $H$. pylori also failed after third-line treatment.

\section{Discussion}

Our study revealed that the eradication rate of TT was below the recommended threshold by both of ITT and
Table 3 Adverse events during first-line Helicobacter pylori eradication therapy

\begin{tabular}{llll}
\hline & $\pi$ & SET & $P$ value \\
& $N=872(74.3 \%)$ & $N=302(25.7 \%)$ & \\
\hline Total & $33(3.8)$ & $10(3.3)$ & 0.706 \\
Diarrhea & $11(1.3)$ & $5(1.7)$ & 0.574 \\
Nausea or vomiting & $9(1.0)$ & $3(1.0)$ & 0.999 \\
Abdominal pain & $8(0.9)$ & $0(0)$ & 0.122 \\
Skin rash & $1(0.1)$ & $1(0.3)$ & 0.448 \\
Metallic taste & $1(0.1)$ & $0(0)$ & 0.999 \\
Others $^{\mathrm{a}}$ & $5(0.6)$ & $2(0.7)$ & 0.999 \\
\hline
\end{tabular}

$\pi$ triple therapy, SET sequential therapy, H. pylori Helicobacter pylori

${ }^{a}$ Others included dyspepsia, bloating, and dizziness

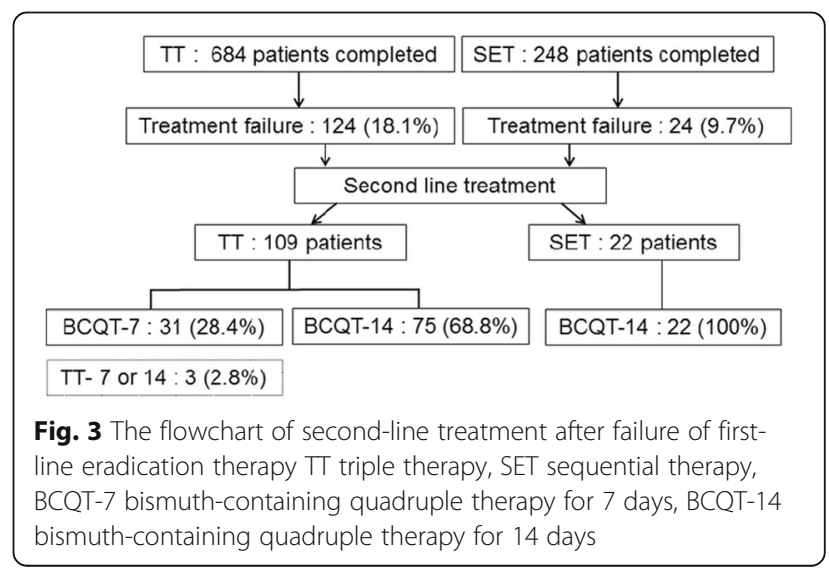


Table 4 Comparisons of second-line treatment after failure of first-line eradication therapy

\begin{tabular}{|c|c|c|c|c|}
\hline & $\begin{array}{l}\Pi \rightarrow \\
\text { BCQT-7 }\end{array}$ & $\begin{array}{l}\Pi \rightarrow \rightarrow \\
\text { BCQT-14 }\end{array}$ & $\begin{array}{l}\mathrm{SET} \rightarrow \\
\mathrm{BCQT}-14\end{array}$ & $P$ value \\
\hline \multicolumn{5}{|l|}{ Eradication rate, \% ( $n$ ) } \\
\hline $\mathrm{ITT}$ & $71(22 / 31)$ & $85.3(64 / 75)$ & $72.7(16 / 22)$ & 0.162 \\
\hline PP & $84(21 / 25)$ & $95.5(64 / 67)$ & $84.2(16 / 19)$ & 0.076 \\
\hline $\begin{array}{l}\text { Compliance > 80\%, } \\
\%(n)\end{array}$ & $80.6(25)$ & $89.3(67)$ & $86.4(19)$ & 0.511 \\
\hline $\begin{array}{l}\text { Adverse events, } \\
\%(n)\end{array}$ & $25.8(8)$ & $22.7(17)$ & $18.2(4)$ & 0.839 \\
\hline
\end{tabular}

$\pi$ triple therapy, SET sequential therapy, BCQT-7 bismuth-containing quadruple therapy for 7 days, BCQT-14 bismuth-containing quadruple therapy for 14 days, $I T T$ intention to treat, $P P$ per protocol

PP analyses. This result is in accordance with the most recent meta-analysis for treatment of $H$. pylori, which concluded that SET was superior than TT showing the overall eradication rate of TT for 69.8 and $77.0 \%$, and SET for 79.7 and $85.0 \%$ by ITT and PP analyses, respectively [14]. The most important cause of decreased efficacy of TT is considered as increasing antibiotic resistant rate, especially to clarithromycin [21]. The eradication rate of $H$. pylori was significantly different depending on the resistance or sensitivity to clarithromycin of the strain; $67.9 \%$ for clarithromycin-resistant strains and $95.5 \%$ for the clarithromycin-sensitive strains [12].

Previous studies proposed several clinical factors associated with $H$. pylori eradication failure including, age, gender, smoking, previous antibiotics usage [22, 23]. The most recent study in Korea reported that female gender could be associated with treatment failure, based on the fact that $H$. pylori strain with point mutation in the $23 \mathrm{~S}$ rRNA were preferentially infected in women which could result in treatment failure with clarithromycin [24]. Also, smoking may increase treatment failure by reducing antibiotics delivery to gastric mucosa, because smoking decreases gastric blood flow and mucus secretion and smoking itself is an indicator for poor compliance [24-26]. However, we could not find any statistically significant clinical factor to predict successful eradication of $H$. pylori.

Our study supports SET as an alternative first-line treatment for several reasons. First, SET achieved reasonable target by both of ITT and PP analyses, whereas TT showed unacceptable efficacy. The reason for relatively higher efficacy of SET for $H$. pylori eradication compared with TT could be based on decreased resistance rate to metronidazole [27], because the resistance to nitroimidazole reduces the efficacy of sequential therapy up to $50 \%[21,28,29]$. The resistance rate to metronidazole was reported 40.5\% during 1994-1999 [30], 49.6\% between 2003 and 2005 [31], and 27.5\% between 2003 and 2009 [12] in Korea. And clarithromycin resistance is thought to have less effect on the efficacy of SET than on TT [32]. Second, treatment-related adverse events of SET were tolerable in most of the patients. There was no patient who discontinued the treatment due to treatment-related adverse event in our study. Also, no significant differences were found regarding overall complication rates or incidence of individual complication between two groups. Third, drug compliance in the SET group was comparable with that of the TT group. There has been concern about complex administration schedule and higher complication rates of SET than TT [14] which could directly influence on drug compliance and possibly lower drug efficacy. But, our study revealed good compliance of the SET group, almost $85.0 \%$, which was not statistically different from the TT group and showed no significant difference regarding adverse events between the two groups. In our medical center, all physicians explained possible treatment-related complications before prescribing medication with sufficient time, and this was also thought to be the cause of good compliance of SET. Fourth, we suggested reasonable treatment option in cases of treatment failure of first-line SET. One of the major concerns of four-drug regimen is choice of second-line treatment when first-line eradication therapy failed, because there could be more chances of acquiring antibiotic resistance [33]. According to the Maastricht IV Consensus Report, BCQT is recommended as optimal second-line treatment [34], and 2013 revised Korean guidelines also recommends BCQT for secondline option after failure of first-line TT [10]. However, there is no definite guideline for the second-line treatment after failure of SET. According to our results, BCQT could be good second-line treatment option after failure of firstline SET.

This study has several limitations. First, test for $H$. pylori identification or antibiotic sensitivity test was not performed which could clarify direct influence of antibiotic susceptibility on eradication rate. Antibiotic resistance rate, especially clarithromycin resistance is significant factor for determining the efficacy of $H$. pylori eradication with TT or SET [24]. Thus, these kinds of tests are the best way to reduce eradication failure arising from antibiotic resistance [21]. But, it is very difficult to test all patients in the general clinics, and costeffectiveness is another problem [21]. In a recent prospective study evaluating the efficacy of SET and amoxicillin/tetracycline containing bismuth quadruple therapy (PBAT) for the first-line eradication in the patients from nine different provinces, SET did not reach the $90 \%$ eradication rate in the PP analysis despite SET was more effective than PBAT [35]. This discordance with our result could be explained by the difference of local antibiotic resistance. In Korea, it has been reported that antibiotics resistance of $H$. pylori is differ according to 
the geographic region. In Seoul where our institution is located, resistance rate to clarithromycin is known to be $14.8 \%$, however above study included the provinces in which showed higher resistance rate compared to Seoul such as Busan (42.1\%) or Gyeonggi (32.5\%) [27], and that might be the cause for the decreased efficacy of SET. The dicision for the appropriate empirical antibiotic therapy should be made based on the data of recentlly updated local antibiotic resistance [11], and therfore nationwide updated data for antibiotic resistance of $H$. pylori should be surveyed.

Second, as this study was conducted retrospectively, there were limitations to obtain detailed medical information such as previous medication history including antibiotics or PPI which could have an influence on eradication failure or diagnosis of $H$. pylori infection. Also, treatment-related adverse events in our study might be down-estimated for the same reason. Compared with previous studies which reported SET-related adverse event rates from 23.3 [14] to $48.0 \%$ [32], there was relatively small number of complications in our study (3.3\%).

Third, this study enrolled the patients only in the single-center, and the majority of them resided in Seoul. So applying the results of this study to another area could have limitation. However, this study has strength in terms of its large number of study subjects and assessment of the efficacy of rescue therapy after failure of first-line eradication therapy.

\section{Conclusions}

The eradication rate of TT was below the recommended threshold. However, SET showed acceptable eradication rate by both ITT $(P=0.001)$ and PP $(P=0.002)$ analyses with comparable adverse events. SET also has reasonable second-line treatment option, BCQT after failure of first-line SET. Therefore, SET could be effective and tolerable candidate for the first-line $H$. pylori eradication therapy.

\section{Abbreviations}

BCQT: Bismuth-containing quadruple therapy; H. pylori: Helicobacter pylori; ITT: Intention to treat; MALT: Mucosa-associated lymphoid tissue; PP: Per protocol; PPI: Proton-pump inhibitor; SET: Sequential therapy; TT: Triple therapy; vs.: Versus

\section{Acknowledgements}

Not applicable.

\section{Funding}

No external funding.

\section{Availability of data and materials}

The datasets generated during and/or analyzed during the current study are available from the corresponding author on reasonable request.

\section{Authors' contributions}

JC- data collection, organization, analysis and interpretation of data, writing and revision of the manuscript.; KS- design the study, analysis and interpretation of data, progress guidance and responsible for the whole study; CT- analysis and interpretation of data; KL- help JC collecting data; JL- help JC collecting data; KL- help JC collecting data; CM- analysis and interpretation of data; SK- analysis and interpretation of data; $\mathrm{HJ}$ - analysis and interpretation of data; SJ- analysis and interpretation of data. All authors have read and approved the final manuscript.

\section{Competing interests}

The authors declare that they have no competing interests.

\section{Consent for publication}

Not applicable.

\section{Ethics approval and consent to participate}

All research and data analysis was approved by the Institutional Review Board of Ewha Medical Research Institute, Ewha Womans University School of Medicine (IRB number; 2016-04-051-002). Informed consent was not required per IRB for this is a retrospective study.

Received: 3 September 2016 Accepted: 18 January 2017

Published online: 21 January 2017

\section{References}

1. Lim SH, Kwon JW, Kim N, Kim GH, Kang JM, Park MJ, Yim JY, Kim HU, Baik GH, Seo GS, et al. Prevalence and risk factors of helicobacter pylori infection in Korea: nationwide multicenter study over 13 years. BMC Gastroenterol. 2013;13:104.

2. Moss SF, Malfertheiner P. Helicobacter and gastric malignancies. Helicobacter. 2007;12 Suppl 1:23-30.

3. Yamada T, Searle JG, Ahnen D, Aipers DH, Greenberg HB, Gray M, et al. Helicobacter pylori in Peptic Ulcer Disease. JAMA. 1994;272:65-69.

4. Leodolter A, Kulig M, Brasch H, Meyer-Sabellek W, Willich SN, Malfertheiner P. A meta-analysis comparing eradication, healing and relapse rates in patients with helicobacter pylori-associated gastric or duodenal ulcer. Aliment Pharmacol Ther. 2001;15:1949-58.

5. Wotherspoon AC, Doglioni C, Diss TC, Pan L, Moschini A, de Boni M, Isaacson PG. Regression of primary low-grade B-cell gastric lymphoma of mucosa-associated lymphoid tissue type after eradication of Helicobacter pylori. Lancet. 1993;342:575-7.

6. Bae SE, Jung HY, Kang J, Park YS, Baek S, Jung JH, Choi JY, Kim MY, Ahn JY, Choi KS, et al. Effect of Helicobacter pylori eradication on metachronous recurrence after endoscopic resection of gastric neoplasm. Am J Gastroenterol. 2014:109:60-7.

7. Lee SY. New guidelines for Helicobacter pylori treatment: comparisons between Korea and Japan. Korean J Gastoenterol. 2014;63:151-7.

8. Abe T, Kodama M, Murakami K, Matsunari O, Mizukami K, Inoue K, Uchida M, Okimoto T, Fujioka T, Uchida T, et al. Impact of helicobacter pylori CagA diversity on gastric mucosal damage: an immunohistochemical study of east-Asian-type CagA. J Gastroenterol Hepatol. 2011;26:688-93.

9. Korean $\mathrm{H}$. Diagnosis and treatment of Helicobacter pylori infection in Korea. Korean J Gastoenterol. 1998:32:275-89.

10. Kim SG, Jung HK, Lee HL, Jang JY, Lee H, Kim CG, Shin WG, Shin ES, Lee YC. Korean college of helcobacter and upper gastrointestinal research. Guidelines for the diagnosis and treatment of helicobacter pylori infection in Korea, 2013 revised edition. Korean J Gastroenterol. 2013;62:3-26.

11. Shin WG, Lee SW, Baik GH, Huh KC, Lee SI, Chung JW, Jung WT, Park MI, Jung HK, Kim HU, et al. Eradication rates of helicobacter pylori in Korea over the past 10 years and correlation of the amount of antibiotics use: nationwide survey. Helicobacter. 2016;21:266-78.

12. Hwang TJ, Kim N, Kim HB, Lee BH, Nam RH, Park JH, Lee MK, Park YS, Lee $\mathrm{DH}$, Jung $\mathrm{HC}$, et al. Change in antibiotic resistance of helicobacter pylori strains and the effect of A2143G point mutation of $23 \mathrm{~S}$ rRNA on the eradication of H. Pylori in a single center of Korea. J Clin Gastroenterol. 2010;44:536-43.

13. Lee JW, Kim N, Kim JM, Nam RH, Chang H, Kim JY, Shin CM, Park YS, Lee $\mathrm{DH}$, Jung $\mathrm{HC}$. Prevalence of primary and secondary antimicrobial resistance of Helicobacter pylori in Korea from 2003 through 2012. Helicobacter. 2013;18:206-14.

14. Lee SW, Kim HJ, Kim JG. Treatment of helicobacter pylori infection in Korea: a systematic review and meta-analysis. J Korean Med Sci. 2015;30:1001-9. 
15. Lam SK, Talley NJ. Report of the 1997 Asia pacific consensus conference on the management of helicobacter pylori infection. J Gastroenterol Hepatol. 1998;13:1-12.

16. Kim N, Kim JJ, Choe YH, Kim HS, Kim JI, Chung IS. Korean college of helicobacter and upper gastrointestinal research; korean association of gastroenterology. Diagnosis and treatment guidelines for helicobacter pylori infection in Korea. Korean J Gastroenterol. 2009;54:269-78.

17. Kim JS, Kim BW, Ham JH, Park HW, Kim YK, Lee MY, Ji JS, Lee BI, Choi H. Sequential therapy for helicobacter pylori infection in Korea: systematic review and meta-analysis. Gut Liver. 2013;7:546-51.

18. Chung JW, Ha M, Yun SC, Kim JH, Lee JJ, Kim YJ, Kim KO, Kwon KA, Park DK, Lee DH. Meta-analysis: sequential therapy is superior to conventional therapy for helicobacter pylori infection in Korea. Korean J Gastroenterol. 2013;62:267-71.

19. Choi WH, Park DI, Oh SJ, Baek YH, Hong CH, Hong EJ, Song MJ, Park SK, Park JH, Kim HJ, et al. Effectiveness of 10 day-sequential therapy for Helicobacter pylori eradication in Korea. Korean J Gastroenterol. 2008:51:280-4

20. Park S, Chun HJ, Kim ES, Park SC, Jung ES, Lee SD, Jang JS, Kwon YD, Keum B, Seo YS. M1053 The 10-day sequential therapy for Helicobacter pylori eradication in Korea: less effective than expected. Gastroenterology. 2009;136(5):A-339-40.

21. Kim SY, Jung SW. Helicobacter pylori eradication therapy in Korea. Korean J Gastroenterol. 2011;58:67-73.

22. Byun YH, Jo YJ, Kim SC, Lee JS, Shin WY, Park YS, Kim SH, Lee HH, Song MH. Clinical factors that predicts successful eradication of Helicobacter pylori. Korean J Gastroenterol. 2006;48:172-9.

23. Cho DK, Park SY, Kee WJ, Lee JH, Ki HS, Yoon KW, Cho SB, Lee WS, Joo YE, Kim HS, et al. The trend of eradication rate of Helicobacter pylori infection and clinical factors that affect the eradication of first-line therapy. Korean J Gastroenterol. 2010;55:368-75.

24. Kim SE, Park MI, Park SJ, Moon W, Choi YJ, Cheon JH, Kwon HJ, Ku KH, Yoo CH, Kim JH, et al. Trends in Helicobacter pylori eradication rates by first-line triple therapy and related factors in eradication therapy. Korean J Intern Med. 2015;30:801-7.

25. Moayyedi P, Chalmers DM, Axon AT. Patient factors that predict failure of omeprazole, clarithromycin, and tinidazole to eradicate Helicobacter pylori. J Gastroenterol. 1997;32:24-7.

26. Suzuki T, Matsuo K, Ito H, Sawaki A, Hirose K, Wakai K, Sato S, Nakamura T, Yamao K, Ueda R, et al. Smoking increases the treatment failure for Helicobacter pylori eradication. Am J Med. 2006;119:217-24.

27. Kim JY, Kim NY, Kim SJ, Baik GH, Kim GH, Kim JM, Nam RH, Kim HB, Lee DH, Jung $\mathrm{HC}$, et al. Regional difference of antibiotic resistance of Helicobacter pylori strains in Korea. Korean J Gastroenterol. 2011;57:221-9.

28. Beek D, De Craen A. A systematic review of Helicobacter pylori eradication therapy - the impact of antimicrobial resistance on eradication rates. Aliment Pharmacol Ther. 1999;13:1047-55

29. Megraud F. H pylori antibiotic resistance: prevalence, importance, and advances in testing. Gut. 2004;53:1374-84.

30. Kim JJ, Reddy R, Lee M, Kim JG, El-Zaatari FA, Osato MS, Graham DY, Kwon DH. Analysis of metronidazole, clarithromycin and tetracycline resistance of Helicobacter pylori isolates from Korea. J Antimicrob Chemother. 2001;47:459-61.

31. Kim N, Kim JM, Kim CH, Park YS, Lee DH, Kim JS, Jung HC, Song IS. Institutional difference of antibiotic resistance of Helicobacter pylori strains in Korea. J Clin Gastroenterol. 2006:40:683-7.

32. Liou JM, Chen CC, Chen MJ, Chen CC, Chang CY, Fang YJ, Lee JY, Hsu SJ, Luo JC, Chang WH, et al. Sequential versus triple therapy for the first-line treatment of Helicobacter pylori: a multicentre, open-label, randomised trial. Lancet. 2013;381:205-13.

33. Olofsson SK, Cars O. Optimizing drug exposure to minimize selection of antibiotic resistance. Clin Infect Dis. 2007;45:S129-36.

34. Malfertheiner P, Megraud F, O'Morain CA, Atherton J, Axon AT, Bazzoli F, Gensini GF, Gisbert JP, Graham DY, Rokkas T, et al. Management of helicobacter pylori infection-the Maastricht IV/Florence consensus report. Gut. 2012;61:646-64.

35. Lee JY, Kim N, Park KS, Kim HJ, Park SM, Baik GH, Shim KN, Oh JH, Choi SC, Kim SE, et al. Comparison of sequential therapy and amoxicillin/tetracycline containing bismuth quadruple therapy for the first-line eradication of Helicobacter pylori: a prospective, multi-center, randomized clinical trial. BMC Gastroenterol. 2016;16:79.

\section{Submit your next manuscript to BioMed Central and we will help you at every step:}

- We accept pre-submission inquiries

- Our selector tool helps you to find the most relevant journal

- We provide round the clock customer support

- Convenient online submission

- Thorough peer review

- Inclusion in PubMed and all major indexing services

- Maximum visibility for your research

Submit your manuscript at www.biomedcentral.com/submit 